\title{
Design of Phototherapy Radiometer with a Measurement Stability
}

\author{
Ayu Dini Megantari' ${ }^{1}$, Syaifudin ${ }^{1}$, and Endang Dian Setioningsih ${ }^{1}$ \\ ${ }^{1}$ Department of Medical Electronics Engineering Technology Politeknik Kesehatan Kementerian Kesehatan Surabaya, Jl. Pucang Jajar Timur No. 10, Surabaya, \\ 60282, Indonesia.
}

\begin{abstract}
The amount of radiation given from the phototherapy lamp (Blue Light) who not right for neonates with hyperbilirubin is feared to cause the bilirubin levels in not decrease accordance with the calculated dose. The purpose of this study is to make a Blue Light calibration device with a stable measurement. The contribution of this research is by determine a sensor who able to measure the irradiation value more accurately between TCS3200 and AS7262 sensor. TCS3200 sensor measures the wavelengths of 470nm, 524nm and 640nm and AS7262 sensor can measure wavelengths of 430-670nm. The results of both sensors are stored in the Electrically Erasable Programmable Read-Only Memory, with the amount of data and the length of measurement can be adjusted according to user needs. Measurement the irradiation value of two sensors is done simultaneously using 3 Watt Light Emitting Diode lamp as a Blue Light simulation where the lamp is placed directly above the sensor and distance of the lamp to the sensor is $10 \mathrm{~cm}, 20 \mathrm{~cm}$, $30 \mathrm{~cm}$, and $40 \mathrm{~cm}$. The average uncertainty value with TCS3200 sensor is 14.65 and the average uncertainty value with AS7262 sensor is 2.17. Type A uncertainty value is based on results of repeated measurements that show how close the measurement results are to the actual value (stable measurement results). The results showed that the average uncertainty value on AS7262 sensor is relatively small, so its mean the measurement results of AS7262 sensor are stable. The author suggests using sensors who capable of reading the value of light radiation without conversion. The results of this study can be implemented to measure the intensity of the lamp and be used as a reference to determining the time of lamp replacement.
\end{abstract}

INDEX TERM Phototherapy, Radiometer, Blue Light, AS7262, TCS3200

\section{INTRODUCTION}

Phototherapy Radiometer is a device used to measure the irradiation value and distribution of exposure over the irradiated surface area by light source on a phototherapy device with a detector that has limited spectral sensitivity[1]. Phototherapy equipment used on newborns (neonates) who have been diagnosed with jaundice due to excessive levels of bilirubin (hyperbilirubin) [2], the process providing therapy is to emit a spectrum of blue light with wavelengths from 450 to $490 \mathrm{~nm}$, the irradiation distance between the neonate and the source of light (lamp) during therapy is $\pm 30-50 \mathrm{~cm} \mathrm{[3]}$.

The effectiveness of phototherapy depends on the quality of the light emitted (wavelength), light intensity (irradiation), body surface area, and the distance between the phototherapy lamp and the object. Based on Neonatology registration data from December 2014 to November 2015, jaundice (buildup of bilirubin in the sclera and skin) was published in full-term neonates in the Hospital of 1093 neonatal cases sought, obtained 165 (15.09\%) cases with jaundice neonatorum [4].
The right use of phototherapy in accordance with the request given by the doctor with the amount of bilirubin levels needed by neonates can reduce the risk of brain damage that must be repaired due to encephalopathy by bilirubin or kernicterus caused by extreme hyperbilirubinemia [5], using photoisomerization and isomerization structure. Through intensive phototherapy, it is expected to reduce serum total bilirubin levels by 1-2 mg / dL in 4-6 hours. Neonates can be said to have normal bilirubin levels if the total serum bilirubin level is $0.3-1.0 \mathrm{mg} / \mathrm{dL}$. Knowing the amount of bilirubin levels in neonates can help determine the appropriate distance between phototherapy devices with neonates and the scheduling of treatments to be applied[6]. LED lights are effective when used for the treatment of jaundice in newborns and require less power and a longer lifetime[7]. However, it does not rule out the possibility that the amount of radiation on LED lights can also be reduced insignificantly depending on the age of use of the lamp[8]. If the baby does not get the right amount of radiation, it is feared that the bilirubin level in the baby will not decrease according to the calculated dose. Needed a radiometer who measure the amount of radiation in the phototherapy lamp to ensure that the baby gets the right amount of radiation. 
Based on the literature results of Radiometry of Phototherapy (Blue Light Therapy) In South Africa [9]. The literature above to measure the irradiation value on the Phototherapy lamp using several Radiometer devices that have different wavelength sensitivity ranges. It has been concluded that the Minolta Fluoro-Lite Meter 451 is a radiometer that is able to measure irradiation values better than other Radiometer devices used. Minolta Fluoro-Lite Meter 451 is able to measure wavelengths between $430-490 \mathrm{~nm}$ with a responsive peak at $450 \mathrm{~nm}$ of 0.85 . The next research, one of the sensors that will be used by the author is AS7262 who able to measure irradiation values with wavelengths between $430-670 \mathrm{~nm}$ with a responsive peak at $500 \mathrm{~nm}$ of 1 [10].

The next literature results, Design of Spectrophotometer for Neonatal Phototherapy [11]. The literature above to design a radiometer using a linear CMOS detector where the output is a series of amplitudes of 256 pixels. Each pixel represents a specific wavelength in nanometers, which must be converted according to polynomials. After that the wavelength will be converted to an irradiation value, therefore it requires twice the conversion process to measure the irradiation value. The next research the author will use a light sensor that is able to measure the irradiation value with one conversion coming from the wavelength of the sensor output, it is hoped that it will be more efficient in making modules.

The next literature results Multifunctional Radiometer, Hospital Equipment, Multiuse Measurement Tools, System and Method for Measuring Irradiance in Phototherapy [12]. The device is able to measure the irradiation value in several types of phototherapy lamps. However, the device is not using the distance sensor yet to measure the distance between the light source with the object of therapy, this becomes less effective because the operator must measure the distance manually. Measurement using this manual can increase the measurement error, considering the effectiveness of use phototherapy is influenced by the distance between the lamp with the neonate, the exact distance measurement results are needed. Another weakness of this device is there is no storage of data measurement result on the device, this condition becomes less effective because of the longer data retrieval process. Phototherapy equipment must be in a proper condition for use at all times given the very high mobility of the equipment use.

The next library search result, has been made Phototherapy Radiometer with AS7262 Sensor[13]. In the library search above there is storage using the SD Card, but the measurement data can only be seen using a PC. This condition is still less effective because it requires more time to see the data that has been stored. The results of the next library search, in accordance with the above agreement, are then submitted to those who want these deficiencies by making a Design of Phototherapy Radiometer Equipped with a Distance Sensor.

\section{MATERIALS AND METHODS}

\section{A. EXPERIMENTAL SETUP}

In this study used 3 Watt LED Lamp as a simulation of Phototherapy Lamp. Irradiation value of the Lamp simulation will be detected by 2 light sensor simultaneously and use a distance sensor for measure the distance between the lamp and the sensor. The data retrieval is repeated for 6 times with 4 distances $(10 \mathrm{~cm}, 20 \mathrm{~cm}, 30 \mathrm{~cm}$, and $40 \mathrm{~cm})$.

\section{B. MATERIALS AND DEVICE}

In this study, used an TCS3200 Color Light Sensor, Adafruit AS7262 6-Channel Visible Light Sensor, and HC-SR04 Ultrasonic Sensor Module. Arduino Uno was used to read an output of the sensor and convert them to irradiation and distance value. User could set the amount of data and the lenght of data retrieval, the retrieval data will save on EEPROM with an 1 Kbyte memory on Arduino Uno.

\section{EXPERIMENT}

In this study, researchers processed Irradiation value using MAV, Standard Deviation, and Uncertainty Value, then see the effect of distance on irradiation value and to know the comparison of the results of the two light sensors.

\section{MAV (Mean Absolute Value)}

MAV is a formula for calculating average values when measurement is repeated several times, the mean value can be calculated. The MAV calculation formula is as follows[14][15].

$$
M=\frac{1}{n} \sum_{k=1}^{n}\left|x_{k}\right|
$$

\section{SD (Standard Deviation)}

The standard deviation describes the dispersion of applicable to the whole population of possible measured values and to estimate the distribution[14][15].

$$
S D=\sqrt{\frac{1}{n-1} \sum_{k=1}^{n}\left(x_{k}-M\right)^{2}}
$$

\section{Ua (Uncertainty Type A)}

Type A evaluation of measurement uncertainty is an error occurred from the statistical distribution of the quantity values from series of measurements[14][15].

$$
U a=\frac{S}{\sqrt{n}}
$$

\section{THE DIAGRAM BLOCK}

Phototherapy lamp radiation will be measured by 2 light sensors, TCS3200 sensor and AS7262 sensor. HC-SR04 sensor will measure the distance between the sensor and the lamp. Digital data from the 3 sensor outputs will be processed using a 
microcontroller that has been programmed to convert digital data into radiation and distance values. Radiation and distances value obtained will be displayed on LCD TFT and stored on an EEPROM. (Fig. 1).

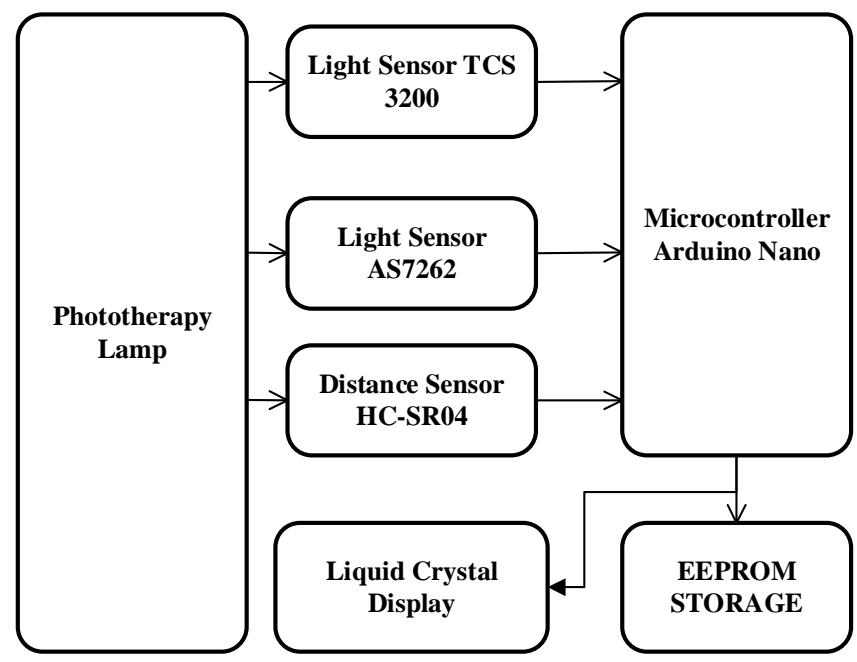

Fig 1. The diagram block

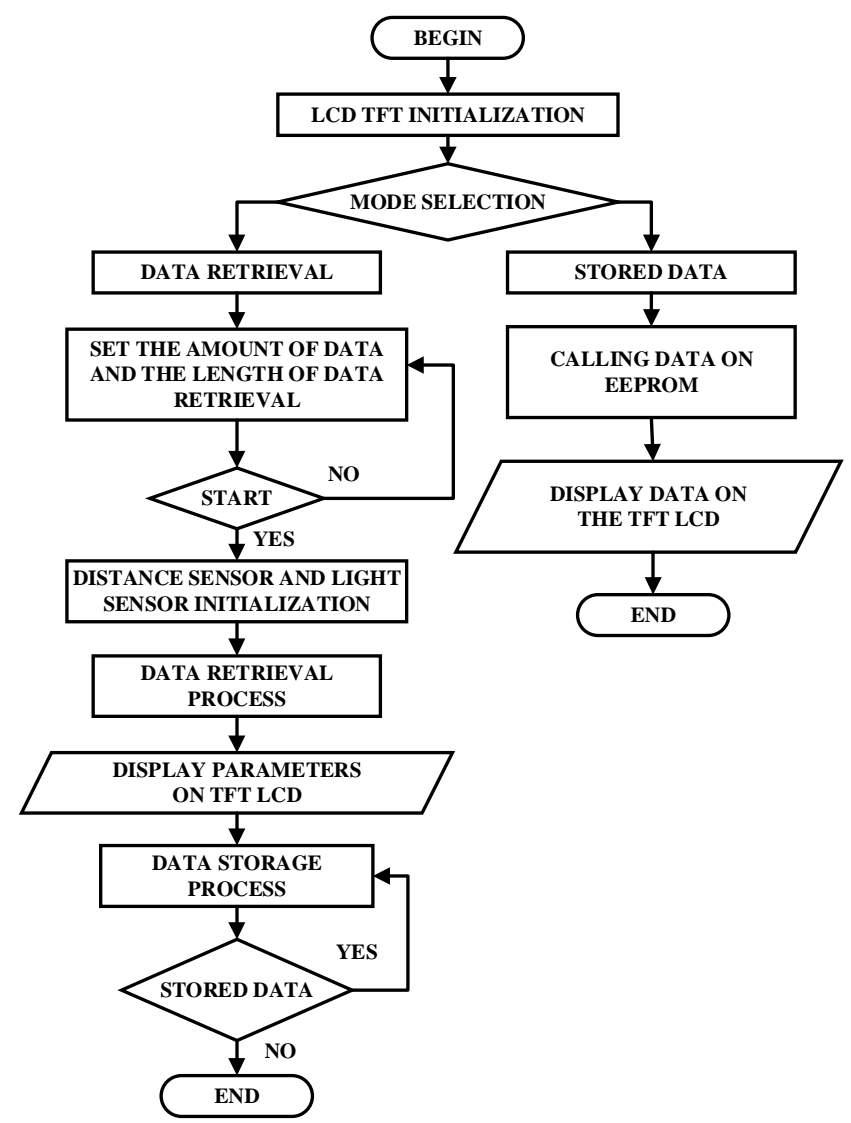

Fig 2. The Flowchart EMG signal processing and extraction feature
In (Fig. 2). The first process starts from Mode selection between data retrieval and stored data. Data retrieval mode there are settings for the amount of data and the length of data retrieval, after settings press the start button to initialization the sensor. The measurement data result will be displayed on the LCD TFT and stored on the EEPROM. Next to the saved data mode, the data will be called from EEPROM and displayed on the LCD TFT.

\section{E. CIRCUIT}

This is a circuit used in research. the circuit used is the AS7262 Sensor, TCS3200 Sensor, HC-SR04 Sensor dan Arduino Uno.

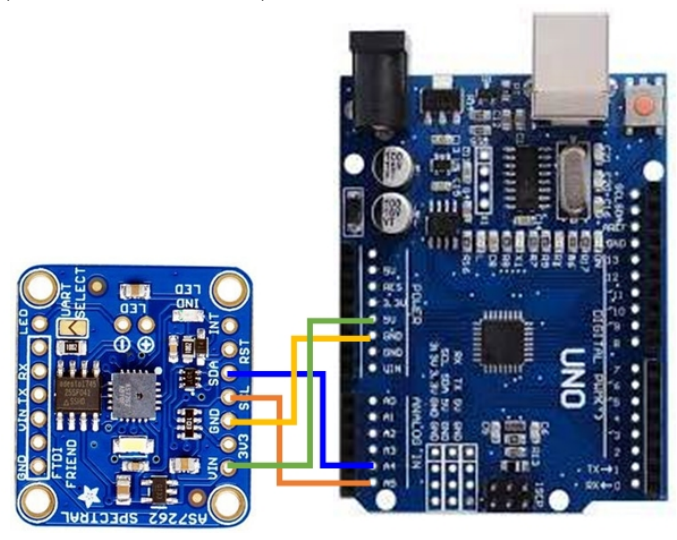

Fig 3. Circuit of AS7262 Sensor and Arduino Uno

Connecting sensor pins 5V, ground, SCL, and SDA with Arduino Uno. The Pin SCL is connected to Pin A5 and Pin SDA to A4 Arduino Uno Pin. Place the sensor under a phototherapy simulation lamp, check the SCL and SDA output using serial data on Arduino Uno and appear the result measurement on LCD TFT (Fig. 3).

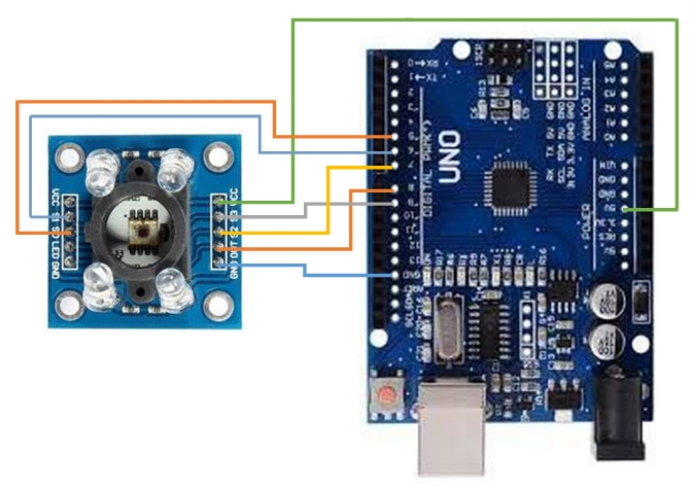

Fig 4. Circuit of TCS3200 Sensor and Arduino Uno

In (Fig. 4), This sensor can detect light colors that function to capture the intensity of a phototherapy simulation lamp. Where the Pin S0 sensor is connected to Pin 5 Arduino Uno, Pin S1 sensor is connected to Pin 6 Arduino Uno, Pin S2 sensor is connected to Pin 7 Arduino Uno, Pin S3 sensor is connected to Pin 9 Arduino Uno, and while the Pin output sensor is 
connected to the Arduino Uno Pin 8 Digital. Place the sensor under a phototherapy simulation lamp, convert the output sensor to the irradiation value and appear the result measurement on LCD TFT.

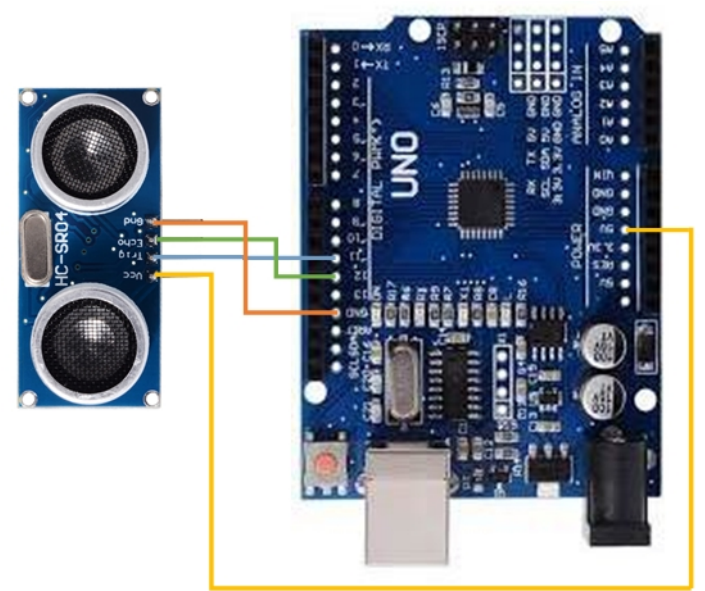

Fig 5. Circuit of AS7262 Sensor and Arduino Uno

Connect Pin 5V, ground, Trig, and Echo sensors to the Pin Arduino Uno. Pin Trig Sensor is connected to Pin 11 Arduino Uno and Pin Echo sensor is connected to Pin 12 Arduino Uno. After that, check the output of Trig and Echo using serial data on Arduino and place the media in front of the Transmitter sensor to be able to reflect ultrasonic waves and be received again by the Receiver sensor (Fig. 5).

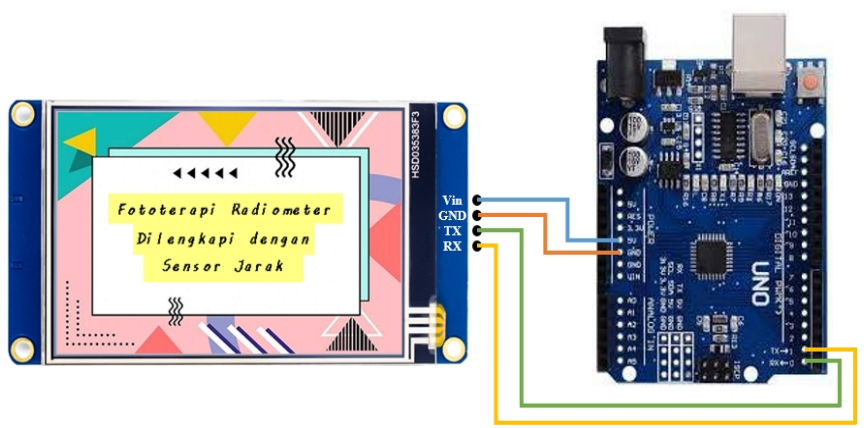

Fig 6. Circuit of LCD TFT and Arduino Uno

Using the LCD TFT it is necessary to make a display design using the Nextion Editor application first. After the display design is created, the design will be uploaded on the LCD TFT using the USB TTL module by connecting all the LCD TFTpins on the USB TTL module. The design that has been uploaded will be saved on the LCD TFT, after the upload process is complete then disconnect the pin. Processing the Arduino Uno program with the design of the LCD TFT display is done by connecting all the LCD TFT pins on the Arduino Uno. Pin TX LCD TFT is connected to Pin 1 (RX) Arduino Uno and Pin RX LCD TFT sensor is connected to Pin 0 (TX) Arduino Uno (Fig. 6).

\section{RESULTS}

\section{A. PHOTOTHERAPY RADIOMETER DEVICE}

The Phototherapy Radiometer device was showed in Fig. 6 as can be seen drawn that the location of the 3 sensors used are separate from the main module. This is done by considering the safety and comfort of the user so as not to be exposed to lights when measuring using radiotherapy phototherapy. The design on the initial LCD TFT display can be seen in Fig. 7.

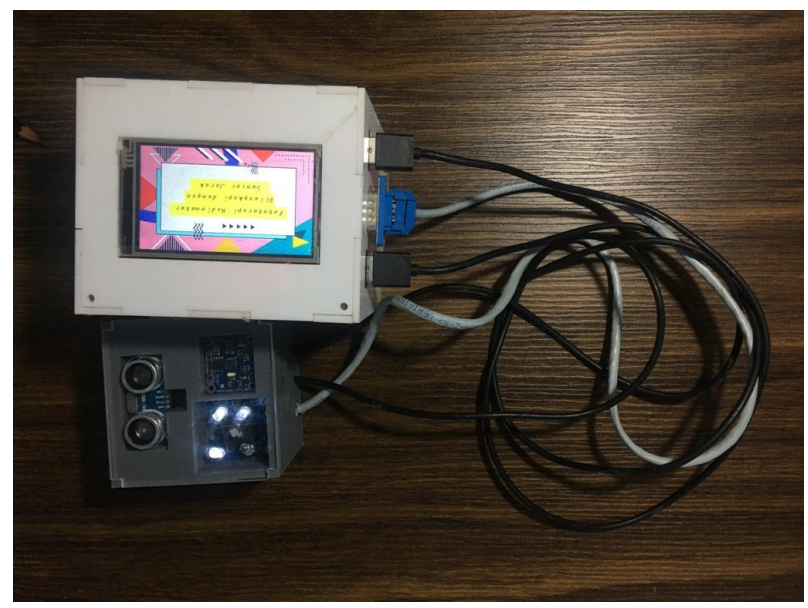

Fig 7. Phototherapy Radiometer Device

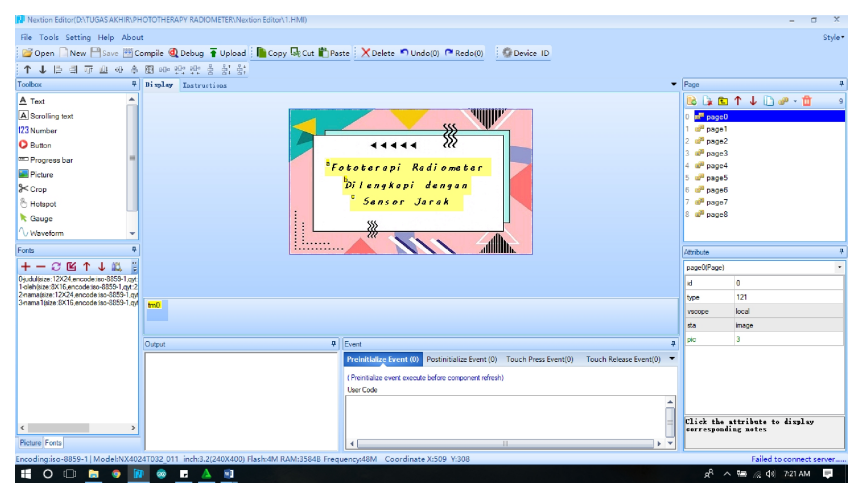

Fig 8. LCD TFT Display Design

\section{B. PHOTOTHERAPY RADIOMETER OUTPUT DISPLAY}

Fig. 8 is one of the displays of the LCD TFT when the Phototherapy Radiometer device measures the distance between the simulation of Phototherapy lamp and the sensor as far as $10 \mathrm{~cm}$. The amount of data and the length of data retrieval set in the image is 3 data in 15 minutes and the irradiation value in the image is taken at the 14 th minute. 


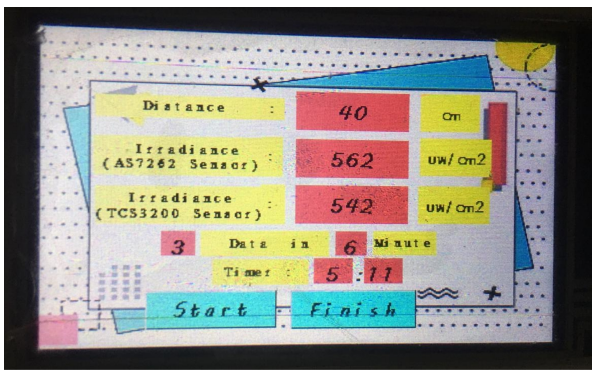

Fig 9. The Measurement of Irradiation Value $(40 \mathrm{~cm})$

Fig. 9 is one of the displays of the LCD TFT when the Phototherapy Radiometer device measures the distance between the simulation of Phototherapy lamp and the sensor as far as $40 \mathrm{~cm}$. The amount of data and the length of data retrieval set in the image is 3 data in 11 minutes and the irradiation value in the image is taken at the 6th minute.

\section{IRRADIANCE VALUE}

Table 1, The results of measurements that have been made using 3Watt LED Lamp as a simulation of Phototherapy lamp obtained uncertainty values because there are still external factors that affect the measurement results, such as the location of the sensor at the time of measurement, sensor distance to the lamp, type of lamp used, lighting of the room when measuring done so that the measurement value is not stable.

TABLE I. The Irradiance Value Using 2 Light Sensor

\begin{tabular}{|c|c|c|c|c|}
\hline \multirow[b]{2}{*}{ Distance } & \multicolumn{2}{|c|}{ MAV } & \multicolumn{2}{|c|}{ SD } \\
\hline & $\begin{array}{l}\text { AS7262 } \\
(\mathrm{W} / \mathrm{cm} 2)\end{array}$ & $\begin{array}{r}\text { TCS3200 } \\
\left(\mathrm{W} / \mathrm{cm}^{2}\right)\end{array}$ & $\begin{array}{l}\text { AS7262 } \\
\left(\mathrm{W} / \mathrm{cm}^{2}\right)\end{array}$ & $\begin{array}{c}\text { TCS3200 } \\
\left(\mathrm{W} / \mathrm{cm}^{2}\right)\end{array}$ \\
\hline $10 \mathrm{~cm}$ & 1825.83 & 1832 & 2.79 & 0.00 \\
\hline $20 \mathrm{~cm}$ & 943.50 & 940 & 5.32 & 9.30 \\
\hline $30 \mathrm{~cm}$ & 654.67 & 629 & 5.35 & 65.07 \\
\hline $40 \mathrm{~cm}$ & 565.67 & 592.67 & 7.84 & 69.20 \\
\hline
\end{tabular}

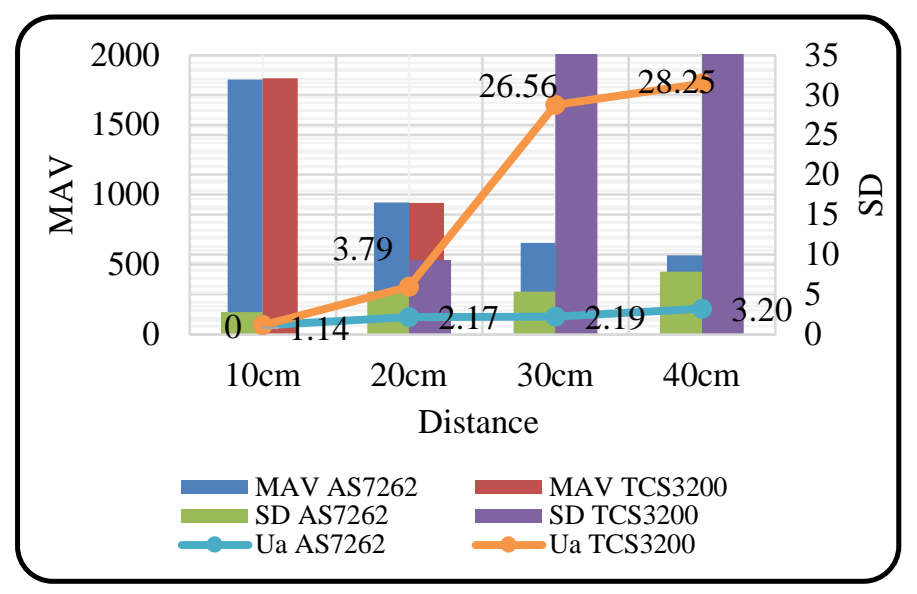

Fig 10. Diagram of Irradiation Value
Fig. 10 shows the irradiation values obtained based on measurements made using a 3 Watt LED Lamp as a Phototherapy lamp simulation. The diagram above shows that the irradiation value of the lamp will get and the stability of the measurement results by the sensor also decreases along with the greater distance value, it can be seen in the graph above where the uncertainty value of the two light sensors is greater when the distance value is also greater.

\section{DISCUSSION}

The phototherapy radiometer design trials have been carried out using a 3 Watt LED lamp with a simulation of a phototherapy lamp. Based on retrieval of data that has been done of the sensor value output, the resulted device can read the irradiation value with distance 10, 20, 30, ad $40 \mathrm{~cm}$. From the Table 1, it can be seen that the largest MAV value on the AS7262 sensor is 1825,83 at $10 \mathrm{~cm}$ distance and the smallest MAV value is 565,67 at $40 \mathrm{~cm}$ distance. while on the TCS3200 sensor the largest MAV value is 1832 at $10 \mathrm{~cm}$ distance and the smallest MAV value is 592,67 at a distance of $40 \mathrm{~cm}$. From the MAV value can calculate the standard deviation to find out the uncertainty value of the measurements made. The average uncertainty value for AS7262 sensors is 2,17 . While the average uncertainty value for TCS3200 sensors is 14,65 .

The performance of this work was also compared to other works. The Literature from "Phototherapy Radiometer with AS7262 Sensor"[13] does not have a feature to measure distance values, in this study also used the AS7262 sensor. The irradiation value of these two works cannot be compared because of the difference in the measured media. However, "Phototherapy Radiometer with AS7262 Sensor"[13] has a smaller average uncertainty value of 1,37 when using the AS7262 sensor.

\section{CONCLUSION}

This study was built based on Arduino Uno, AS7262 sensor, TCS3200 sensor, HC-SR04 sensor, LCD TFT, and Save the data on EEPROM. This study has proofed that irradiation value inversely proportional with the distance between a lamp and the sensor. Irradiation result from 2 sensor light that is AS7262 and TCS3200 has been compared, and note that the average uncertainty value of the AS7262 sensor is smaller than the average uncertainty value of the TCS3200 sensor.

\section{REFERENCES}

[1] S. M. Reda, K. A. Mohammad, and S. M. El-faramawy, "Construction and characterization of a phototherapy radiometer for optical radiation measurements," Indian J. Pure Appl. Phys., vol. 56, no. 5, pp. 379-382, 2018.

[2] Addi, Mitra Mohd, Nur Azimah Zainal Abidin, and Siti Asmah Daud. "Development of a portable phototherapy garment (PPG) for jaundice treatment." In 2016 IEEE EMBS Conference on Biomedical Engineering and Sciences (IECBES), pp. 405-410. IEEE, 2016.

[3] Glickman, Gena, Brenda Byrne, Carissa Pineda, Walter W. Hauck, and George C. Brainard. "Light therapy for seasonal affective disorder with blue narrow-band light-emitting diodes (LEDs)." Biological psychiatry 59, no. 6 (2006): 502-507..

[4] Nuntnarumit, Pracha, and Chonlathit Naka. "Comparison of the effectiveness between the adapted-double phototherapy versus 
conventional-single phototherapy." Journal of the Medical Association of Thailand = Chotmaihet Thangphaet 85 (2002): S1159-66..

[5] P. M. Licla, E. Laura Bravo, G. Kemper, J. L. Villalobos, C. Del Carpio, and C. D. Aliaga, "A Method of Irradiance Distributing over an Effective Irradiated Area for Phototherapy Lamps," Proc. 2018 IEEE 25th Int. Conf. Electron. Electr. Eng. Comput. INTERCON 2018, no. D, pp. 9-12, 2018, doi: 10.1109/INTERCON.2018.8526373.

[6] Pineda-López, Flavio, Paúl Ayala Taco, Katherine Cajas Narváez, Silvana Vargas Salinas, Roberto Pineda López, Derlín Morocho, and Rosario Pineda López. "Light blue led for bilirubin treatment in newborns: Automatic photherapy prototype." In 2017 IEEE XXIV International Conference on Electronics, Electrical Engineering and Computing (INTERCON), pp. 1-4. IEEE, 2017..

[7] L. Jimenez, L. Vilcahuaman, and J. Galdos, "Development and thermal assessment of a blue light emitting diode phototherapy device for neonatal jaundice treatment in Kangaroo mother care," 2016 IEEE Healthc. Innov. Point-of-Care Technol. Conf. HI-POCT 2016, pp. 37-41, 2016, doi: 10.1109/HIC.2016.7797691.

[8] Van Imhoff, Deirdre E., Christian V. Hulzebos, Maaike van der Heide, Vera W. van den Belt, Hendrik J. Vreman, Peter H. Dijk, and BARTrial Study Group. "High variability and low irradiance of phototherapy devices in Dutch NICUs." Archives of Disease in Childhood-Fetal and Neonatal Edition 98, no. 2 (2013): F112-F116.

[9] Coblentz, William Weber, M. J. Dorcas, and Charles Wesley Hughes. Radiometric measurements on the carbon arc and other light sources used in phototherapy. No. 539. US Government Printing Office, 1926.

[10] Nasr, Ismail, Reinhard Jungmaier, Ashutosh Baheti, Dennis Noppeney, Jagjit S. Bal, Maciej Wojnowski, Emre Karagozler et al. "A highly integrated $60 \mathrm{GHz}$ 6-channel transceiver with antenna in package for smart sensing and short-range communications." IEEE Journal of SolidState Circuits 51, no. 9 (2016): 2066-2076..

[11] Svobodova, B., M. Penhaker, V. Kasik, M. Augustynek, and J. Kubicek. "Design of spectrophotometer for neonatal phototherapy." In 2017 IEEE 15th International Symposium on Applied Machine Intelligence and Informatics (SAMI), pp. 000417-000422. IEEE, 2017.

[12] Rodrigues, Djalma Luiz, and Orlando Rossi Filho. "Multifunctional radiometer, hospital equipment, multiuse measurement tool, system and method for measuring irradiance in phototherapy." U.S. Patent Application 13/512,818, filed November 8, 2012..

[13] Bahtiar, Ichwan Syahrul, Andjar Pudji, and I. Dewa Gede Hari Wisana "Phototherapy radiometer with AS7262 sensor." Journal of Electronics, Electromedical Engineering, and Medical Informatics 1, no. 1 (2019): 3945.

[14] Komite Akreditasi Nasional, "00003/Eks-KAN-Ped/PTBBI | KAN Pd01.03 Guide On The Evaluation And Expression of Uncertainty in Measurement," p. 30, 2019.

[15] Taylor, Barry N., and Chris E. Kuyatt. "Guidelines for evaluating and expressing the uncertainty of NIST measurement results." (1994).. 


\section{APPENDIX}

A. Listing program for Setting the Amoung of Data and the Length of Data Retrieval

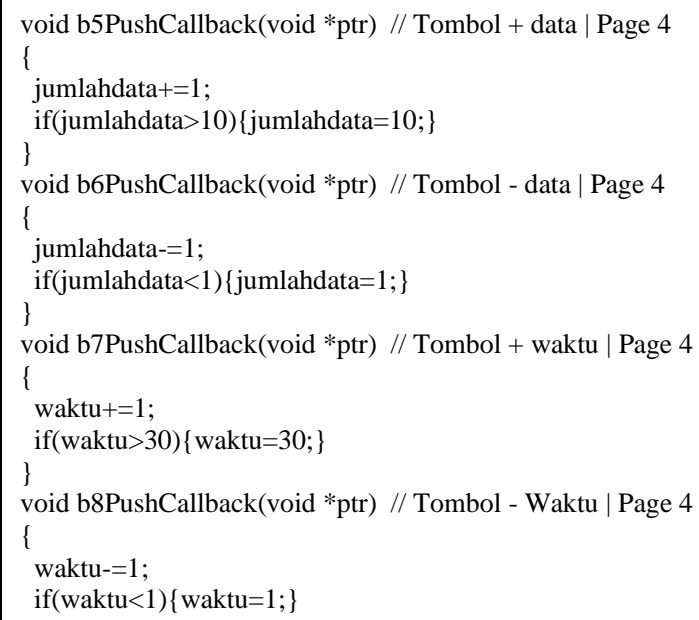

The above program functions to set the up and down buttons when setting the amount of data and the length of data retrieval. Up button for "jumlahdata" can increase numbers until 10 data and the down button "jumlahdata" can increase numbers until 1 data. Then Up button for "waktu" can increase numbers until 30 minutes and the down button can increase numbers until 1 minute.

B. Listing program for Read The Output Values from AS7262 Sensor

\{ ams.startMeasurement(); //begin a measurement

//wait till data is available

bool rdy = false;

while(!rdy)

\{

delay(5);

rdy $=\operatorname{ams} . d a t a R e a d y() ;$ \}

//read the values!

ams.readRawValues(sensorValues);//Membaca output sensor iradiance $=($ sensorValues $[$ AS726x_BLUE] $) ; / /$ Pembacaan cahaya bir delay(20); \}

. The above program functions to read the raw data coming from the sensor output and convert it to an irradiation value.

\section{Listing program for Read The Output Values from TCS3200 Sensor}

The Program down below functions to read the raw data coming from the sensor output and convert it to an irradiation value.
digitalWrite(S2,LOW);// Setting filter photodiodes untuk pembacaan digitalWrite(S3,HIGH);

// Reading the output frequency

frequency = pulseIn(sensorOut, LOW);

//Remaping the value of the frequency to the RGB Model of 0 to 255 frequency $=\operatorname{map}($ frequency, $25,70,255,0)$;

blue $=$ frequency;

delay(100);

rata2=blue;

$\mathrm{Pc} 2=\mathrm{P} 2+$ varProcess 2

$\mathrm{G} 2=\mathrm{Pc} 2 /(\mathrm{Pc} 2+$ varVolt2 $) ; \quad / /$ kalman gain

$\mathrm{P} 2=(1-\mathrm{G} 2) * \mathrm{Pc} 2$

$\mathrm{Xp} 2=\mathrm{Xe} 2$

$\mathrm{Zp} 2=\mathrm{Xp} 2$

yRata2 $=(65.064 *($ pow $($ fillata2,2) $))-(719.28 *$ filRata 2$)+2518.4$

//if (yRata2<500 || yRata2 $>4000)\{$ yRata2 $=0 ;\}$

if (yRata2 $>=500 \& \&$

yRata2 $<=4000)\{y \operatorname{Rata2map}=\operatorname{map}(y \operatorname{Rata} 2,2236,1557,1096,602) ;\}$

delay (200);

\}

D. Listing program for Read The Output Values from HC-SR04 Sensor

digitalWrite(trigPin,LOW);

delayMicroseconds(5);

digitalWrite(trigPin,HIGH);

delayMicroseconds $(10)$;

digitalWrite(trigPin,LOW);

pinMode(echoPin,INPUT);

duration=pulseIn(echoPin,HIGH);

$\mathrm{cm}=($ duration/2)/29.1

//Serial.print $(\mathrm{cm})$;

delay (250);

\}

The above program functions to read the raw data coming from the sensor output which form of duration and convert it to an distance value.

E. Listing program for Send the sensor Values to LCD TFT

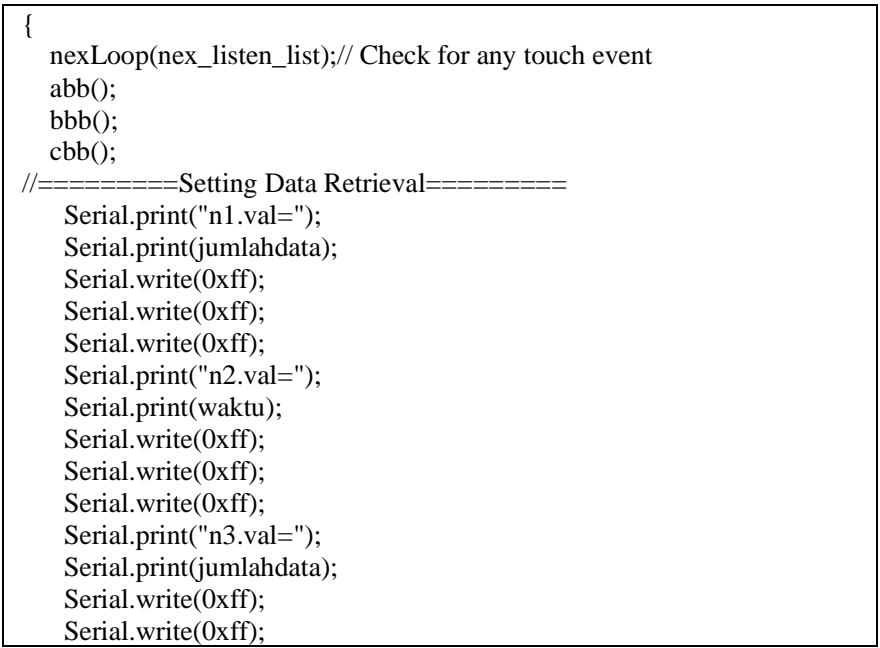




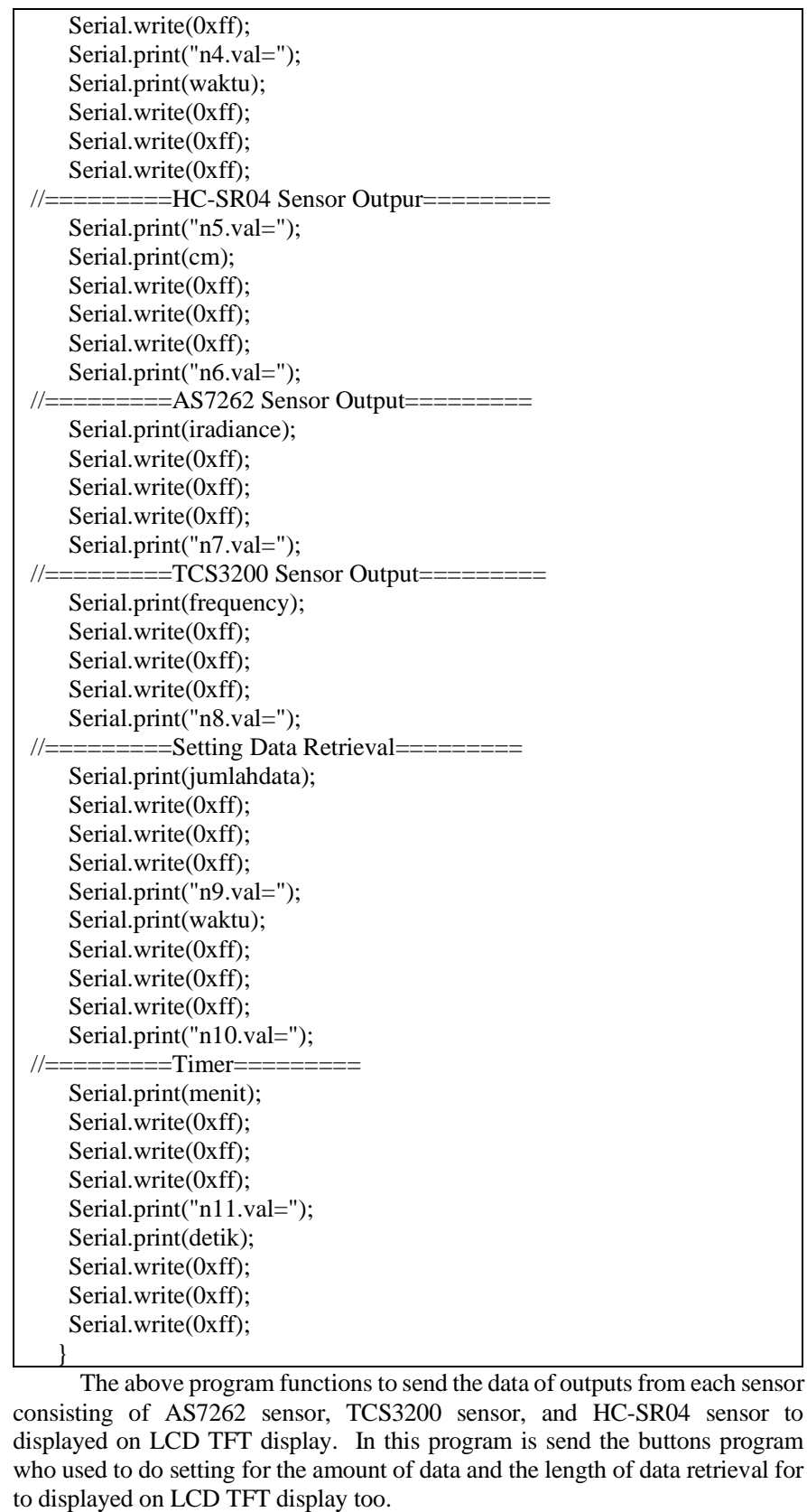

